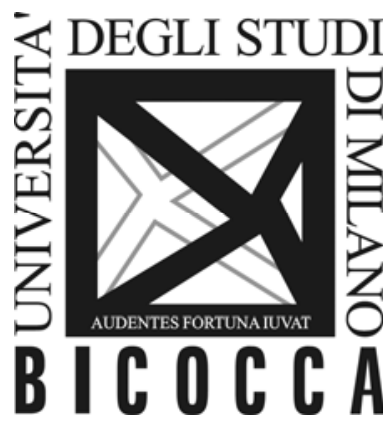

DEPARTMENT OF ECONOMICS

UNIVERSITY OF MILAN - BICOCCA

WORKING PAPER SERIES

\title{
Education and selective vouchers
}

\author{
Amedeo Piolatto \\ No. 177 - January 2010
}

Dipartimento di Economia Politica

Università degli Studi di Milano - Bicocca

http://dipeco.economia.unimib.it 


\title{
Education and selective vouchers*
}

5th January 2010

\section{Amedeo Piolatto **}

\author{
U. de Alicante
}

\begin{abstract}
A widely accepted result in the literature is that the majority of voters are against the introduction of universal vouchers. Chen and West (2000) predict that voters' attitudes towards selective vouchers (SV) may be different. They claim that voters are indifferent between the no-voucher and $\mathrm{SV}$ regimes, unless competition leads to a reduction in the education price. I show that, when public schools are congested, the majority of voters are in favour of SV. Furthermore, SV induces a Pareto improvement. In equilibrium, the introduction of SV induces a reduction in income stratification at school, with some relatively poor students attending private schools.
\end{abstract}

JEL Classification number: H42, I20, I22, I28, I29, D70

Keywords: positive public economics; education; vouchers; voting

*I thank D. Checchi, M. Bordignon, G. Glomm, M. Justman, P. Pestieau, R. Romano and an anonymous referee for the helpful comments and suggestions and especially F. Boffa, O. Carbonell-Nicolau, G. Casamatta, Ph. De Donder, M. Gilli, I. Iturbe-Ormaetxe, J. Masso, P. Natale and D. Siniscalco for supporting and advising me. I also thank participants in the 5ème Journée G. Varet (Marseille), ID Workshop (C. Carlo Alberto - Torino) and colleagues at U. Bicocca (Milan), TSE (Toulouse) and UAB (Barcelona). Support from the Spanish Ministry of Education under the grant SEJ2007-62656 is gratefully acknowledged. A working paper version of this paper was published in 2009 by Ivie (AD09-10), which I acknowledge for the financial support.

** Departamento de Fundamentos del Análisis Económico, apartado de correos 99, 03080 - San Vicente del Raspeig (Alicante) - Spain. Email: piolatto@merlin.fae.ua.es 


\section{Introduction}

Most Western countries publicly provide private goods, such as education, financed through taxes and offered to citizens at a lower-than-competitive price. Households can choose between the public and private supplies; legal or technical reasons may prevent households from consuming both simultaneously, a common assumption in the education literature.

Consumers' preferred quality of instruction is heterogeneous. For equity reasons, and because of the limited available resources, all students in a public school receive the same service, regardless of their preferences. Some agents may prefer private to public school for different reasons (congested public schools, availability in private schools of a broader variety of courses, etc.). Incentives to move to the private sector increase agents' decisional space and can relax the public budget constraint. Meanwhile, political support for a high-quality public service may decrease when more people attend private schools.

Vouchers provide an incentive to attend private schools; ${ }^{1}$ their use was recently implemented in a variety of countries (Chile was amongst the first; the Czech Republic one of the last). The introduction of vouchers often encounters strong ideological opposition; ${ }^{2}$ I use a political economy model to investigate how citizens would perceive the introduction of a voucher system. A voting model seems appropriate to forecast how voters would perceive changes in the level of taxation and the use of vouchers. ${ }^{3}$

The idea behind the model is that public school students receive a sub-optimal level of instruction. A voucher allowing them to attend a private school induces some voters to opt out of the public sector and choose the optimal budget share to devote to education. Proposing a voucher of value below the cost of public school students relaxes public budget constraint, when only people that would otherwise attend public school are entitled to use it. By revealed preferences, people opting out of the public sector are better off. The new budget allows for an increase in the quality of public school and a reduction of the tax burden, making all voters better off.

A broad part of the literature concludes that vouchers do not improve welfare

\footnotetext{
${ }^{1}$ Vouchers are either "universal" (everybody receives them) or "selective" (only a subset of the population is eligible).

${ }^{2}$ See Card and Krueger (1992), Filer and Munich (2001), McEwan and Carnoy (2002) or Chakrabarti (2008).

${ }^{3}$ I consider a direct voting model: with office-motivated politicians, the choice of the legislator coincides with the preferred policy by the majority of voters. See also Budge (2006).
} 
or that the majority of citizens are against their introduction (unless additional concerns, such as peer effects, are introduced). I show that 1) their introduction benefits the majority of society; 2) an office-motivated politician should be in favour of their instauration; and 3) introducing vouchers can lead to a Pareto improvement.

The literature on the political economy of education is extensive; ${ }^{4}$ Epple and Romano (1996) is often the departure point (including in my contribution). Education is a consumption good. ${ }^{5}$ Agents, who have heterogenous income, vote over the tax rate to finance public schools; differences in consumption are in terms of quality. An equilibrium may fail to exist; Epple and Romano (1996) identify two single crossing conditions that guarantee its existence: Slope Rising in Income (SRI) and Slope Decreasing in Income (SDI). ${ }^{6}$ Under SRI, the "ends against the middle" equilibrium implies that the richest and poorest households push to reduce the tax, while the middle class does the opposite. Under SDI, the median voter is decisive, and the poorest half of society forms a coalition against the richest half. Vouchers are not considered.

Chen and West (2000) use Epple and Romano (1996)'s structure to compare systems with universal, selective and no vouchers, under SDI. The median income is the upper threshold for receiving selective vouchers of value equal to the (constant) marginal cost of education. They conclude that the majority always prefers the no-voucher model to the universal one. The decisive voter is indifferent between the selective and the no-voucher framework and there are no welfare differences. The crucial assumptions are as follows: a) introducing vouchers does not affect the market price; b) the value of the voucher is equal to the marginal cost of a student; and c) only agents with income below the median are entitled to vouchers. Section III in Chen and West (2000) acknowledges that an increase in competition may lead to a fall in the market price or an increase in quality and, thus, to an increase in welfare. This last result is in line with those of my paper.

Epple and Romano (1998) consider a universal vouchers model with students differing in income and ability. They conclude that a majority of voters supports universal vouchers and that vouchers reduce congestion. Their results rely on

\footnotetext{
${ }^{4}$ Stiglitz (1974) is one of the most well known. Other important contributions come from Glomm and Ravikumar (1992), Blomquist and Christiansen (1999), Chen and West (2000), De Fraja (2002), Gradstein and Justman (2002) and Epple, Romano, and Sieg (2006). The Handbook of the Economics of Education (2006) and Gradstein, Justman, and Meier (2005) provide surveys of a consistent part of the recent literature on the field.

${ }^{5}$ See Dur and Glazer (2008).

${ }^{6}$ Footnote 8 and page 6 provide more details on these conditions.
} 
the presence of peer effects. Rich or skilled students attend private schools. A minority of neither rich nor skilled students remains in public schools, where the quality drops along with students' utility.

Similarly to Chen and West (2000), I consider selective vouchers as a possible way to reduce congestion (reducing the price of private education, vouchers allow some voters to consume it) and to increase quality in the public sector. The differences in results with respect to Chen and West (2000) come from the attributes of the vouchers: more people are entitled to use them and their value is below the marginal cost of public school students. The market structure and the cost function in my model are similar to those in Epple and Romano (1998).

Agents vote on the tax to finance public schooling. The cost of public and private education do not need to be the same. As in Chen and West (2000), I do not consider peer effects, ${ }^{7}$ and I also focus on the SDI condition. ${ }^{8}$ Absent vouchers, the results are identical to those in Epple and Romano (1996), which I use as a benchmark. My model shows that, in the extreme case, the public sector collapses when the share of public school students attracted by vouchers exceeds a given threshold. In this case, a minority of the population may be worse off. In the more realistic case in which public education is not undermined, introducing vouchers is Pareto improving.

The paper is divided into five sections. Section 2 describes the model, Section 3 illustrates the voting outcome without vouchers (benchmark case). Section 4 studies the effects of introducing vouchers, while Section 5 analyses the results of the vote over the tax and show under which conditions selective vouchers induce a Pareto improvement. The last section concludes.

\section{The model}

I consider a model with two normal goods: the numeraire $b$ and education $X$ :

1. Attendance to public and private schools are mutually exclusive. Subscript

\footnotetext{
${ }^{7}$ This is not just a simplifying assumption; despite the massive use of peer effects in the literature, it is still unclear how peer effects operate and which impact they have. See, for instance, Burke and Sass (2008), McEwan (2003), or Zimmerman (2003).

${ }^{8}$ It is unclear which of SDI and SRI is more likely. Justman. contrary to Epple and Romano, suggest that SDI is more appropriate. The SDI (Slope Decreasing in Income) condition means that agents' preferred tax decreases with income; it derives from a substitution effect that prevails on the income effect (vice versa for SRI). SRI is more reasonable for countries where the living conditions of the poorest citizens are dramatic in absolute terms (children tend not to attend school). Thus, education has a small impact on poor people's utility. SDI is more appropriate when poor people are rich enough to consider education as an investment.
} 
$P$ indicates the public sector and $R$ the private sector (e.g., $X_{P}$ and $X_{R}$ are respectively the qualities of public and private education).

2. The mass of voters is normalised to 1. Each voter has a pupil of school age. Voters type depends solely on income $\omega$, distributed with density $f$ on the support $\left[\omega_{\min }, \omega_{\max }\right]$. I assume the average (and aggregate) income $\bar{\omega}=\int_{\omega_{\min }}^{\omega_{\max }} \omega f(\omega) d \omega$ to be greater than the median one $\left(\omega_{\text {med }}\right)$.

3. Voters' utility function, $U(X, b)$, is separable and strictly concave in $X .^{9}$

4. The school cost function is convex in the number of students $n: C(X, n)=$ $F+V(n) X$, with $V^{\prime}(n) \geq 0$ and $V^{\prime \prime}(n) \geq 0$. In particular, I assume $V(n)=$ $c_{1} n+c_{2}(n)^{2}$; thus, the cost function is $C(X, n)=F+\left(c_{1} n+c_{2}(n)^{2}\right) X .{ }^{10}$

5. The public sector is the dominant firm, while the private sector is the competitive fringe. The shape of the cost function is the same for both the public and private sectors. Without loss of generality, I assume that only one public institute is present. ${ }^{11}$ Each private school student decides the level of educational quality to purchase. Low barriers to entry ensure that the number of students in each school adjusts to the efficient scale (i.e., for each firm $i$, $\left.n_{i}=\arg \min \left(\frac{C\left(X, n_{i}\right)}{n_{i}}\right)\right)$. The quality of one unit of private education $X_{R}$ is defined in order to normalise the private sector's price to one. ${ }^{12}$

6. Public education is financed via a proportional income tax $t$ paid by all citizens and chosen through majority voting. Without loss of generality, I suppose that the public budget constraint requires balancing only ordinary (variable) costs and the proportional income tax proceeds. ${ }^{13}$

7. Tax proceeds are first used to finance vouchers. ${ }^{14}$ The remaining resources are shared equally among public school students (thus, all students attending public school receive the same quality of education $X_{P}$ ).

\footnotetext{
${ }^{9}$ This assumption is slightly more restrictive than necessary. It allows to simplify the subsequent computations without affecting results and insights.

${ }^{10}$ Appendix A discusses this assumption.

${ }^{11}$ Equivalently, assume that public schools are of equal size and provide the same service.

${ }^{12}$ By the free entry assumption, the price of private school does not depend on the number of students in the private sector. Chen and West (2000) arrives at the same conclusion through a generic technology to produce education showing decreasing returns to scale. Epple and Romano (1996) do not specify the private sector market structure.

${ }^{13}$ In other words, fixed costs are covered by ad hoc lump sum taxes. This assumption has no qualitative effect on the results.

${ }^{14}$ Fixing a minimal expenditure for public schools might imply a higher preferred tax, but it would not qualitatively affect the outcome. Having total income shared between vouchers and public school would reduce tractability without adding special insights.
} 
8. The value $v$ of vouchers and agents eligible to use them are exogenously determined. The public cost of vouchers is $n_{v} v$, where $n_{v}$ is the number of people using vouchers in equilibrium. ${ }^{15}$

By assumption 6, total public (variable) expenditure $\left(c_{1}+c_{2} n_{p}\right) n_{p} X_{P}+n_{v} v$ must equal tax proceeds $t \bar{\omega}$. Rearranging the budget constraint, the quality of public schools is defined by:

$$
X_{P}=\frac{t \bar{\omega}-n_{v} v}{g n_{p}}
$$

where $g=\left(c_{1}+c_{2} n_{p}\right)$ is the per-pupil cost of one unit of public education. Since $X_{P}$ cannot be negative, we must ensure that $t \bar{\omega} \geq n_{v} v$. The convexity assumption plays an important role in the model. I discuss my choice in appendix A, where I also introduce an alternative assumptions leading to similar results with a linear cost function.

\subsection{Households' behaviour}

- The problem of an agent choosing private school is ${ }^{16}$

$$
\left\{\begin{array}{l}
\max _{X_{R}} U\left(X_{R}, b\right) \\
\text { s.t. } \quad b=(1-t) \omega-\max \left\{X_{R}-v ; 0\right\}
\end{array}\right.
$$

The indirect utility (in reduced form) is $U^{R}\left(X_{R}^{*},(1-t) \omega-\max \left\{X_{R}^{*}-v ; 0\right\}\right)$, where $X_{R}^{*}$ is the optimal level of consumption of private education. Not profiting from public education, his preferred tax rate if he uses vouchers is $t=\frac{n_{v} v}{\bar{\omega}}$ (the minimum tax to finance them) and $t=0$ otherwise. His utility is strictly decreasing with the tax.

- The utility function of an agent of income $\omega$ attending public school is $U\left(X_{P}, b\right)$; replacing $b$ with the after tax income and $X_{P}$ with Equation 1,

\footnotetext{
${ }^{15}$ Voting over the tax to finance school only, excluding vouchers' value and who is eligible, is not just a simplifying assumption. The voting mechanism is intended as a way to predict the attitude of an "office-motivated" politician. Voters are interested in general policies (such as the share of GDP devoted to education), while they do not have a clear position on technical problems (such as the value of the voucher) requiring the collection of much information. For instance, the Swiss referendum was only on the introduction of vouchers. Their value and who could profit from them were chosen by politicians.

${ }^{16}$ Remember that the price of private education $q$ is normalised to 1 .
} 
the indirect utility is:

$$
U^{P}\left(\frac{t \bar{\omega}-n_{v} v}{g n_{p}} ;(1-t) \omega\right)
$$

The tax rate $t^{*}(\omega)=\underset{t}{\arg \max } U^{P}\left(\frac{t \bar{\omega}-n_{v} v}{g n_{p}},(1-t) \omega\right)$ maximises agent's utility. The preferred tax depends on income; from the FOC changes are measured implicitly. By the separability of $U, \frac{\partial t^{*}(\omega)}{\partial \omega}>0$ (SRI) if and only if $-\omega(1-t) U_{22}^{P}>U_{2}^{P}$ and $\frac{\partial t^{*}(\omega)}{\partial \omega}<0$ (SDI) if and only if $-\omega(1-t) U_{22}^{P}<U_{2}^{P} \cdot{ }^{17}$

Both conditions, widely accepted in the literature, refer to agents attending public school; I assume that the SDI assumption holds. This assumption means that the marginal utility of education is larger than that of the numeraire for low income voters, and smaller for high income agents. As a consequence, richer people are less eager to substitute units of the numeraire for education.

Each agent chooses between public and private school by comparing the two levels of utility that he can attain. It is possible to identify the "indifferent vo$\operatorname{ter}(\mathrm{s})$ " $\widehat{\omega}$, i.e., the voter(s) having the same utility regardless of the type of school attended:

$$
U^{R}\left(X_{R}^{*},(1-t) \omega-\max \left\{X_{R}^{*}-v, 0\right\}\right)=U^{P}\left(\frac{t \bar{\omega}-n_{v} v}{g n_{p}},(1-t) \omega\right)
$$

The identity of $\widehat{\omega}$ depends on public school quality and thus on the equilibrium $\operatorname{tax} t$. Since the equilibrium tax depends on the identity of the pivotal voter $\underline{\omega}$, it is more precise to denote the indifferent voter by $\widehat{\omega}(\underline{\omega})$.

From the following two lemmas, once we identify the indifferent voter, all richer agents attend private school and the others attend public school. ${ }^{18}$

Lemma 1 In a given interval $\omega \in[\alpha, \varphi]$ and for $\alpha<\beta<\varphi$, if the agent $\omega=\beta$ prefers the private system so do all those richer than him (i.e., $\omega \in[\beta, \varphi]$ ).

Lemma 2 Similarly to the previous lemma, if $\omega=\beta$ prefers the public system, so do all the poorer agents (i.e., $\omega \in[\alpha, \beta]$ ).

The intuition is that the choice between public and private education depends on the marginal rate of substitution (monotone in income) between education and the numeraire. When an agent is sufficiently rich for private school to be preferable (because the reduction in consumption of $b$ has minor effects), this is true a fortiori

\footnotetext{
${ }^{17}$ For more on the SRI and SDI assumptions, see Epple and Romano (1996).

${ }^{18}$ This is true, provided we compare agents all receiving a voucher or if none of them did it.
} 
for all richer agents. Similarly, if an agent prefers public school, then poorer people prefer it too.
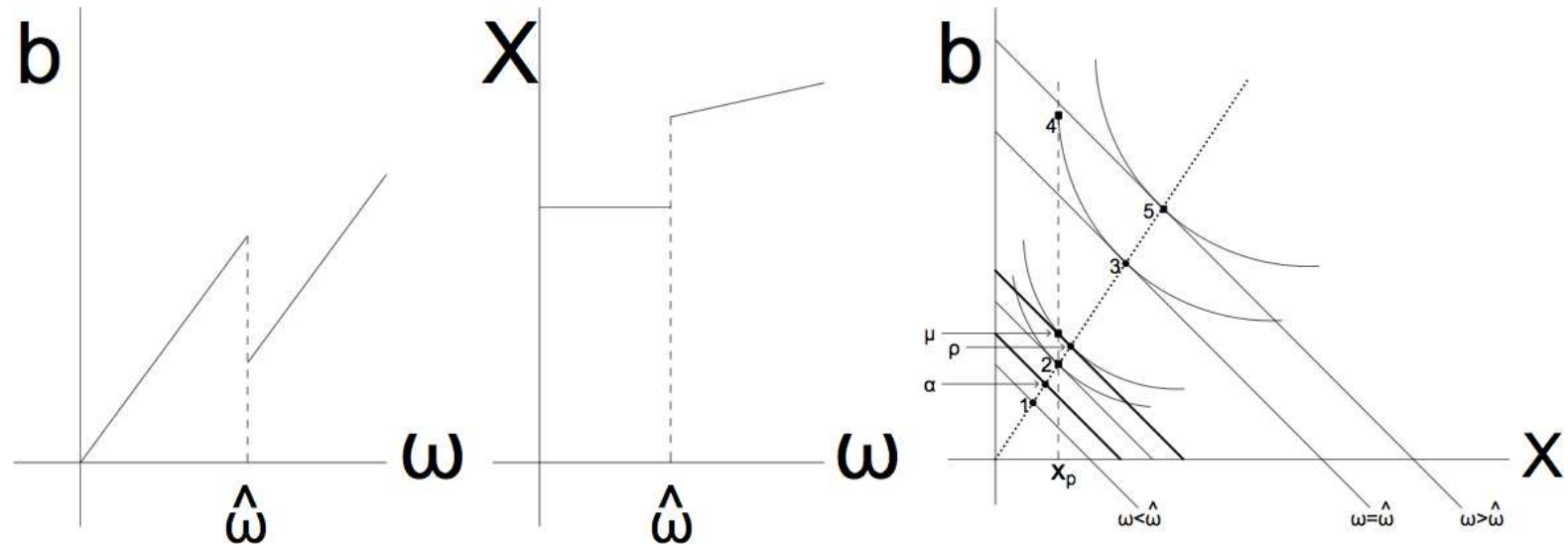

Figure 1: Moving from public to private school: Engel's and indifference curves

The indifferent agent can choose between two bundles: attending public school (point 4 in Figure 1) he can consume more of the numeraire but less education than desirable (point 3) and vice versa (the centre and left charts in fig. 1 show the jump in consumption), since agents pay the tax financing the public school also when attending private school. From the sketch of the indifference curves (right chart in Figure 1), ${ }^{19}$ for an agent with low income $(\omega<\hat{\omega})$, and in particular for the median voter, it is preferable to attend public school $(2 \succ 1)$. Voter $\hat{\omega}$ is indifferent between public and private instruction $\left(3 \sim_{\hat{\omega}} 4\right)$. Finally, for those agents with sufficiently large income $(\omega>\hat{\omega})$, the point of tangency suggests that the private schooling is preferred.

Before considering the solution of the model, I consider the situation when vouchers are not available, a benchmark to study the consequences of the introduction of vouchers.

\section{The benchmark case: no vouchers}

Absent vouchers, this model differs from Epple and Romano (1996) only in that the cost function parameters can differ from the public to the private sector. ${ }^{20}$ Equilibrium results for the no-voucher case are denoted by the superscript $n v$. Equation

\footnotetext{
${ }^{19}$ The vertical dashed line in correspondence to the point $X_{p}$ shows the possibility of consumption jump when switching from private to public school. The dotted line represents, with homothetic preferences, the income expansion path.

${ }^{20}$ For more details and proofs of this section results, the reader can see Epple and Romano (1996) and Glomm and Ravikumar (1998).
} 
1 becomes $X_{p}^{n v}=\frac{t \bar{\omega}}{g^{n v} n_{p}^{n v}}$ and 3 is $U^{R}\left(X_{R}^{*},(1-t) \omega-X_{R}^{*}\right)=U^{P}\left(\frac{t \bar{\omega}}{g^{n v} n_{p}^{n v}},(1-t) \omega\right)$.

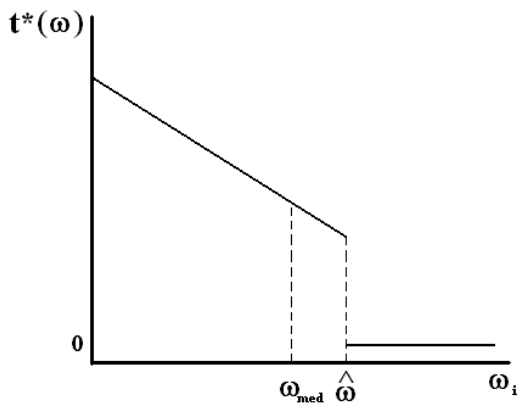

Figure 2: Preferred tax under SDI and no voucher (linear proxy)

Under the SDI assumption, the median voter is pivotal $\left(\underline{\omega}=\omega_{m e d}\right)$ (see Figure $2) .^{21}$ This means that the voting outcome in the no-voucher case is $t^{n v}=t\left(\omega_{\text {med }}\right)$; all and only agents with income lower than the indifferent voter $\widehat{\omega}$ attend public school. The number of households attending public school is $n_{p}^{n v}\left(t^{n v}\right)=$ $\int_{\omega_{\min }}^{\widehat{\omega}} f(\omega) d \omega=F(\widehat{\omega}) \cdot{ }^{22}$

Compared to Epple and Romano (1996), public and private school prices (respectively $g$ and $q$ ) can differ. Their results for the SDI case hold assuming $g=q$. When $g \neq q$, their results are still qualitatively applicable; but the identity of the indifferent voter changes. Relative to Epple and Romano (1996), if $g>q$, the quality of public school is lower, and so is $\widehat{\omega}$ (i.e., the indifferent agent is poorer); the opposite is true for $g<q$.

\section{Introducing vouchers}

Agents with income below $\omega_{\max }^{v}=\widehat{\omega}\left(t^{n v}\left(\omega_{\text {med }}\right)\right)$ are entitled to use a voucher of magnitude $v=\frac{t^{n v} \bar{\omega}}{n_{p}^{n v}}$ if they attend a private school; ${ }^{23}$ the two values were arbitrarily chosen: $v$ is equal to the voucher-absent average cost of a public school

\footnotetext{
${ }^{21}$ The preferred tax is weakly decreasing in income; $t<t\left(\omega_{\text {med }}\right)$ cannot be an equilibrium because households with income $\omega<\omega_{\text {med }}$ prefer $t\left(\omega_{\text {med }}\right)$, nor can $t>t\left(\omega_{m e d}\right)$, which is defeated by a majority including agents with income $\omega \geq \omega_{\text {med }}$.

${ }^{22}$ Agents take $n_{p}^{n v}$ (thus the quality of public instruction) as given and vote for the tax level. In equilibrium, the proportion of voters opting for public services coincides with agents' expectations. Glomm and Ravikumar (1998)'s proposition 2 (proving that a value for $n_{p}^{n v}$ always exists that solves 3 and that this value is unique) holds in this framework. Glomm and Ravikumar (1998)'s proposition 2 holds under not restrictive conditions: the cumulative density function $F(\omega)$ has to be continuous and increasing in $\omega$.

${ }^{23}$ By the decreasing returns to scale assumption, the value of the voucher is strictly smaller than the marginal cost of a student in equilibrium in the case without vouchers, i.e., $\frac{t^{n v} \bar{\omega}}{n_{p}^{n v}}<$ $\frac{\left(c_{1}+2 c_{2} n_{p}^{n v}\right) t^{n v} \bar{\omega}}{\left(c_{1}+c_{2} n_{p}^{n v}\right) n_{p}^{n v}}$.
} 
student; $\omega_{\max }^{v}$ is the income of the indifferent agent under no vouchers. This ensures that agents attending private schools anyway are not subsidised, and it simplifies comparisons with the no-voucher framework.

The public budget constraint 1 can be rewritten as

$$
X_{P}=\left(t-\frac{n_{v}}{n_{p}^{n v}} t^{n v}\right) \frac{\bar{\omega}}{g n_{p}}
$$

We expect some of the agents entitled to receive a voucher to shift to the private sector. This implies a reduction in congestion. Thus, the quality of public school increases, possibly attracting some students who previously attended private schools.

Since the price of private education is no longer the same for all agents, we identify up to two possible indifferent agents: one among voters receiving vouchers and another within the others.

It is preferable to consider the two groups $\left[\omega_{\min }, \omega_{\max }^{v}\right]$ and $\left[\omega_{\max }^{v}, \omega_{\max }\right]$ separately. Lemmas 1 and 2 allow us to construct four (possibly empty) subsets: ${ }^{24}$ in particular, for each of the two previous groups of agents, some voters may prefer public education and others the private one.

$\widehat{\omega}_{L}(t) \in\left[\omega_{\min }, \omega_{\max }^{v}\right]$ is the income level for which

$$
U^{R}\left((1-t) \omega-X_{R}^{*}+v\right)=U^{P}\left(\frac{t \bar{\omega}-n_{v} v}{g n_{p}},(1-t) \omega\right)
$$

while $\widehat{\omega}_{R}(t) \in\left[\omega_{\max }^{v} ; \omega_{\max }\right]$ is such that

$$
U^{R}\left((1-t) \omega-X_{R}^{*}\right)=U^{P}\left(\frac{t \bar{\omega}-n_{v} v}{g n_{p}},(1-t) \omega\right)
$$

Equations 5 and 6 mean that agents with income $\widehat{\omega}_{L}$ and $\widehat{\omega}_{R}$ are indifferent between private and public education; $\widehat{\omega}_{L}+v \leq \widehat{\omega} \leq \widehat{\omega}_{R}$.

Figure 3 shows how utility changes with income for an agent attending private or public school, both with and without vouchers. The quality of public school in the graph is fixed and $X_{p}>X_{p}^{n v}$.

If $U^{R}(\omega+v)$ and $U^{P}\left(X_{p}, \omega\right)$ were crossing to the right with respect to $U^{R}(\omega)$ and $U^{P}\left(X_{p}^{n v}, \omega\right)$, than $\widehat{\omega}_{L}$ would be greater than $\widehat{\omega}$ and would not belong to the required interval; all agents in $\left[\omega_{\min }, \omega_{\max }^{v}\right]$ would attend public school. Likewise, all agents with income greater than $\widehat{\omega}$ prefer private education when $U^{R}(\omega)$ and

\footnotetext{
${ }^{24}$ Later, I state the existence conditions for the indifferent agents and the bounds of the four subsets'.
} 


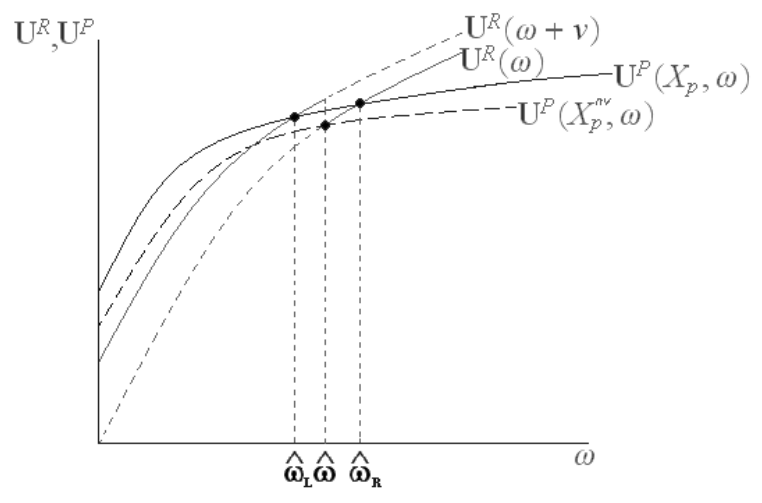

Figure 3: How utility changes with income

$U^{P}\left(X_{p}, \omega\right)$ do not cross to the right of $\widehat{\omega}$. When both thresholds exist, there are four groups of agents, whose preferred choice is represented in Figure 4.

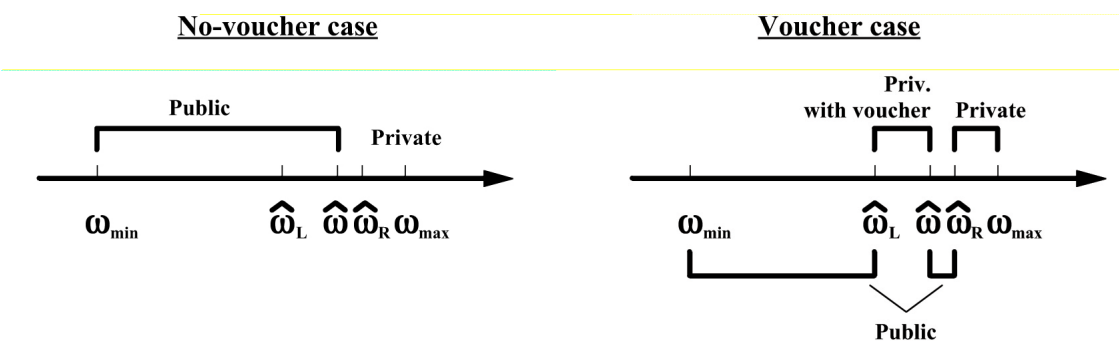

Figure 4: Intervals and choices

Given $\widehat{\omega}_{L}$ and $\widehat{\omega}_{R},{ }^{25}$ the number of agents using the voucher in equilibrium is $n_{v}=\int_{\widehat{\omega}_{L}}^{\widehat{\omega}\left(t^{n v}\right)} f(\omega) d \omega$ while the number of agents attending public school is

$$
n_{p}=\int_{\omega_{\min }}^{\widehat{\omega}_{L}} f(\omega) d \omega+\int_{\widehat{\omega}\left(t^{n v}\right)}^{\widehat{\omega}_{R}} f(\omega) d \omega
$$

The following propositions prove that $\widehat{\omega}_{L} \in\left[\omega_{\min }, \omega_{\max }^{v}\right]$ and $\widehat{\omega}_{R} \in\left[\omega_{\max }^{v}, \omega_{\max }\right]$. Proofs follow in the Appendix.

Proposition 1 For all $t \in(0,1)$ and $\bar{\omega} \in R_{++}$, there always exists a value for $n_{p} \in(0,1)$ for which the number of people willing to attend public school is equal to the one that agents anticipate to solve their maximisation problem.

Proposition 1 guarantees the existence of an equilibrium.

Proposition 2 The tax preferred by an agent of given income falls if, ceteris paribus, the quality of public school increases.

\footnotetext{
${ }^{25}$ The share $n_{p}^{n v}$ of people attending public school under no-voucher is defined on page 8.
} 
Corollary 1 The same pivotal voter might choose different tax rates according to the framework. If $X_{p}>X_{p}^{n v}$, then $t\left(\omega_{m e d}\right)<t^{n v}\left(\omega_{m e d}\right)$.

If the quality of public schooling increases by the introduction of vouchers, then the tax burden decreases when the median voter is pivotal under both regimes. Corollary 1 has an important welfare implication, since a reduction in $t$ generates an increase in all agents' welfare, including private school students.

Proposition 3 If $\widehat{\omega}_{L}=\widehat{\omega}$, then $\widehat{\omega}_{R}=\widehat{\omega}$ and we are back to the case without vouchers. Moreover it cannot be that $\widehat{\omega}_{L}>\widehat{\omega}$.

Intuitively, an agent who (voucher-absent) prefers private school, move to the public sector only if the quality of public school increased. Public school attendance in the vouchers regime is weakly smaller than in the no-voucher one: $g n_{p} \leq g^{n v} n_{p}^{n v}$ with strict inequality if $\widehat{\omega}_{L}<\widehat{\omega}$. As long as (and only when) $\widehat{\omega}_{L}<\widehat{\omega}$, the introduction of vouchers modifies the equilibrium, reducing the number of public school students.

Proposition $4 \widehat{\omega}_{R}>\widehat{\omega}$ if and only if $X_{P}>X_{p}^{n v}$ : some agents move, after the introduction of vouchers, from the private to the public sector, only if the quality of public school increased as a consequence of the change. If $X_{p} \leq X_{p}^{n v}$, then $\widehat{\omega}_{R}=\widehat{\omega}$.

The median voter's preferred tax is the largest supported by at least half of the population); the equilibrium one can never be larger. Since $\widehat{\omega}_{R}>\widehat{\omega}$ only when $X_{p}>X_{p}^{n v}$, if we observe $\widehat{\omega}_{R}>\widehat{\omega}$, the total number of agents attending public school is necessarily smaller than without vouchers $\left(n_{p}<n_{p}^{n v}\right)$.

Proposition 5 Public-school-quality at the equilibrium under vouchers is always greater or equal to the one without vouchers (given the tax rate), i.e., $X_{p} \geq X_{p}^{n v}$, with strict inequality when $\widehat{\omega}_{L}<\widehat{\omega}$.

Proof. See the Appendix for the proofs.

By propositions 1 to 5, there are two possible scenarios after introducing vouchers: a) nobody uses vouchers and the introduction does not affect agents in the economy, that is $\widehat{\omega}_{L}=\widehat{\omega}_{R}=\omega_{\text {max }}^{v}$; or b) the richest people entitled to use vouchers and the poorest who are not eligible both adjust their behaviour: $\widehat{\omega}_{L}<\omega_{\max }^{v}<\widehat{\omega}_{R}$. 


\section{The vote over the tax}

Households chose the tax rate through a majority vote. Agents' preferred tax depends on the choice between public and private education, and on the opportunity to receive a voucher. Recall that:

- the preferred tax rate is decreasing in income (SDI assumption).

- the preferred tax is $t=0$ for private school students not using vouchers.

- $t=\frac{n_{v} v}{\bar{\omega}}$ is the preferred tax of private school students using vouchers. This is the tax needed to finance vouchers. ${ }^{26}$ With this level of taxation, strictly lower than the one preferred by any public school student, public education disappears.

The voting outcome depends on the distribution of income and on whether the median voter attends public school. I analyse the following cases separately: i) (Subsection 5.1) where the median voter attends public school after the introduction of vouchers $\left(\widehat{\omega}_{L} \geq \omega_{\text {med }}\right)$ and vouchers induce a Pareto improvement; and ii) (Subsection 5.2) where the median voter uses the voucher to move to the private sector $\left(\widehat{\omega}_{L}<\omega_{\text {med }}\right)$ and we observe a Pareto improvement only if the public school system does not collapse.

\subsection{The median voter attends a public school $\left(\widehat{\omega}_{L} \geq \omega_{m e d}\right)$}

Focusing on when $\widehat{\omega}_{L} \in\left[\omega_{\text {med }}, \widehat{\omega}\right),{ }^{27}$ the outcome of the vote is precisely $t=t\left(\omega_{\text {med }}\right)$. Agents with income $\omega<\omega_{\text {med }}$ (half of the population) ask for a tax increase with respect to $t=t\left(\omega_{m e d}\right)$, while the others favour a decrease in the equilibrium tax: the median voter is pivotal. Figure 5 represents agents' preferred tax in the case of vouchers when $\widehat{\omega}_{L} \geq \omega_{\text {med }}$.

Even though the median voter is decisive, his preferred tax rate is lower than in the no-voucher case by Proposition 2: $t\left(\omega_{\text {med }}\right)<t^{n v}\left(\omega_{\text {med }}\right)$. The public budget constraint is relaxed and the quality of public school necessarily increases. ${ }^{28}$ This effect is partially offset by the arrival of new students, who previously attended private school and are attracted by the higher public school quality; the subset

\footnotetext{
${ }^{26}$ Vouchers' value is fixed; voting for a larger tax rate is not rational.

${ }^{27}$ If $\widehat{\omega}_{L}=\widehat{\omega}$ (i.e., vouchers are not attractive), we are back to the no-voucher case (proposition $3)$.

${ }^{28}$ Since the voucher's value is below marginal cost, convincing students to move to the private sector relaxes the public budget constraint, increasing the quality of the public service.
} 


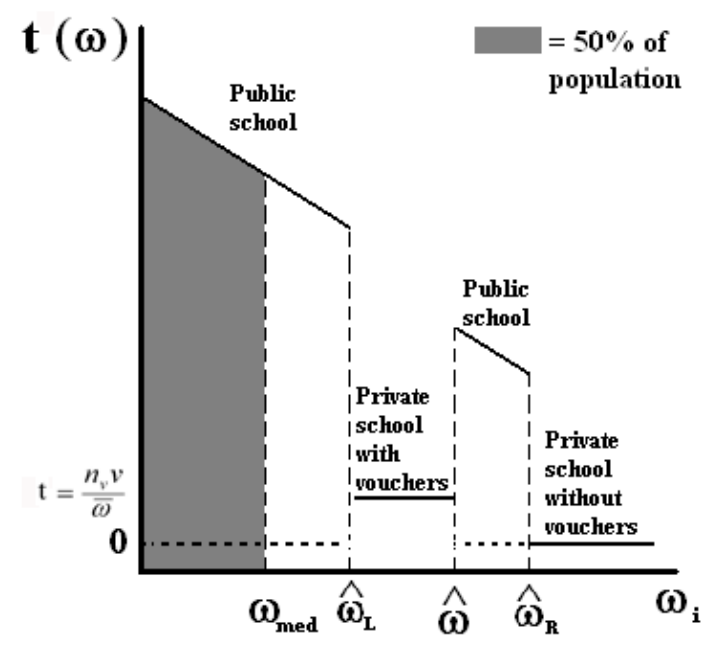

Figure 5: Agents' preferred tax

$\omega \in\left[\widehat{\omega}, \widehat{\omega}_{R}\right]$ is non-empty. By Proposition 4, the number of agents moving out from public school is larger than the number of students moving into it and the final effect is an increase in the quality of the public service (financed through tax proceeds net of vouchers expenditure).

From a welfare standpoint, we observe a Pareto improvement. The quality of public schools increases when vouchers are introduced, making public school students better off. Moreover, the tax burden falls, so all citizens are better off. By the Weak Axiom of Revealed Preferences (WARP), all agents changing behaviour while the previous bundle is still affordable must be better off.

To be more rigorous, for $\widehat{\omega}_{L}<\widehat{\omega}$, utility increases for all agents when introducing vouchers:

- $\left[\omega_{\min }, \widehat{\omega}_{L}\right]$ : these agents always opt for public school. The quality of public school increases (Proposition 5). Since their disposable income and the public school quality increase, their utility increases as well.

- $\left[\widehat{\omega}_{L}, \widehat{\omega}_{R}\right)$ : they either move from public to private education, using vouchers, or from private to public $\left(\omega \in\left(\widehat{\omega}, \widehat{\omega}_{R}\right)\right)$. For all of them, the bundle previously consumed is still affordable. They all have a larger disposable income and the quality of public school increased. If they modify their choice, the new bundle is preferred to the previous one by WARP.

- $\left[\widehat{\omega}_{R}, \omega_{\max }\right]$ : all the agents in this interval attend private school in both cases. The price that they pay to attend private school is the same, and the tax decreases. As a consequence, they are better off in the voucher case. 
To sum up, when the introduction of vouchers is ineffective (i.e., $\widehat{\omega}_{L}=\widehat{\omega}=\widehat{\omega}_{R}$ ), agents are indifferent, and for $\widehat{\omega}_{L} \in\left[\omega_{\text {med }}, \widehat{\omega}\right)$, the selective voucher system strictly Pareto dominates the no-voucher system.

\subsection{The median voter attends a private school $\left(\widehat{\omega}_{L}<\omega_{\text {med }}\right)$}

According to the density function $f(\omega)$, the number of people affected by the introduction of vouchers $\left(\omega \in\left[\widehat{\omega}_{L}, \widehat{\omega}_{R}\right]\right)$ varies, as does the number of agents willing to use vouchers in equilibrium. The consequence of introducing vouchers depends on how many agents move to private schooling.

If $\widehat{\omega}_{L}\left(\omega_{\text {med }}\right)<\omega_{\text {med }}$, the poorest part of the population (which attends public school) cannot form a majority coalition. The shift from public to private induced by vouchers (ceteris paribus) increases the quality of public service, which attracts a group of voters $\left(\omega \in\left[\omega, \widehat{\omega}_{R}\right]\right)$ previously attending a private school. Two scenarios can occur depending on whether or not those willing to attend public school make up at least half of the population (i.e., $\int_{\omega_{\min }}^{\widehat{\omega}_{L}} f(\omega) d \omega+\int_{\widehat{\omega}}^{\widehat{\omega}_{R}} f(\omega) d \omega \geq 50 \%$ ). The value of vouchers and $f(\omega)$ jointly determine which is the relevant scenario. ${ }^{29}$

Let us define the pivotal voter as

$$
\underline{\omega}=\left\{\omega \in\left(\widehat{\omega}, \widehat{\omega}_{R}\right]: \int_{\omega_{\min }}^{\widehat{\omega}_{L}} f(\omega) d \omega+\int_{\widehat{\omega}}^{\underline{\omega}} f(\omega) d \omega=50 \%\right\}
$$

where we restrict the existence of $\underline{\omega}$ to the interval $\left(\widehat{\omega}, \widehat{\omega}_{R}\right]$, to ensure that he is attending a public school. ${ }^{30}$ Intuitively, the income $\underline{\omega}$ represents the agent whose preferred tax is the "median preferred-tax". Agents' preferred tax is summarised in Figure 6.

The existence of $\underline{\omega}$ implies that a coalition of public school students set the equilibrium tax and that the group in favour of having no tax does not influence the vote outcome. If no one income fulfils the requirements in Equation 8, the tax is chosen by the group of agents attending private school and profiting from the voucher (and set to the minimum level to finance vouchers: $t=\frac{n_{v} v}{\bar{\omega}}$ ).

The equilibrium when the majority of voters attend public school By construction, $\underline{\omega}$ is pivotal: agents with income in the interval $\left[\omega_{\min }, \widehat{\omega}_{L}\right] \cup[\widehat{\omega}, \underline{\omega}]$

\footnotetext{
${ }^{29}$ Note that in all countries in which vouchers have been introduced, public school attendance exceeds half of the population. For instance, in Chile, where vouchers' value was set slightly below the average cost of students attending public school (OECD (1998)), private school attendance grew from $25 \%$ to $39 \%$ (Cox and Lemaitre (1999)).

$30 \int_{\omega_{\min }}^{\widehat{\omega}_{L}} f(\omega) d \omega+\int_{\widehat{\omega}}^{\omega} f(\omega) d \omega=50 \%$ is equivalent to $\int_{\widehat{\omega}_{L}}^{\omega_{\text {med }}} f(\omega) d \omega=\int_{\widehat{\omega}}^{\frac{\omega}{\omega}} f(\omega) d \omega$.
} 

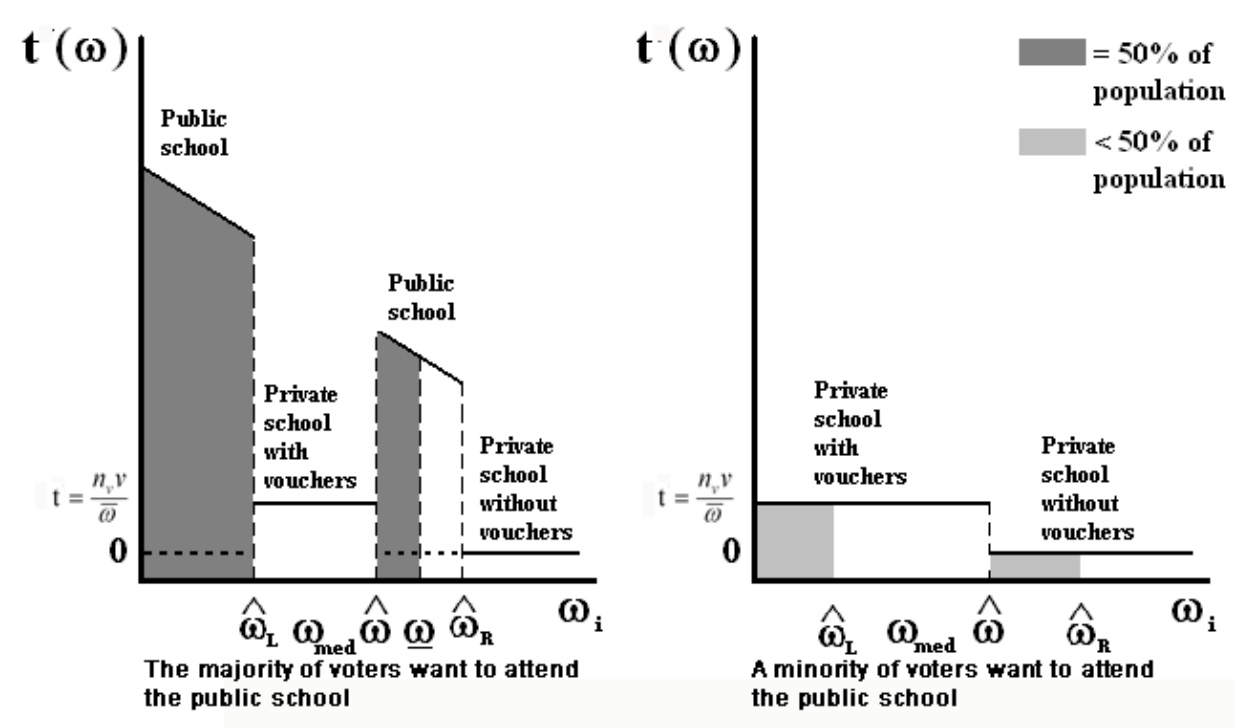

Figure 6: Agents' preferred tax

(representing half of the population) prefer a tax rate larger than the one chosen by $\underline{\omega}$. Agents in $\left[\widehat{\omega}_{L}, \widehat{\omega}\right]$ and $\left[\underline{\omega}, \widehat{\omega}_{R}\right]$ ask for a lower but positive tax rate; the remaining $\left(\omega>\widehat{\omega}_{R}\right)$ ask for no tax at all. By the SDI assumption, since $\underline{\omega}>\omega_{\text {med }}$, the equilibrium tax decreases with respect to those in Sections 3 and 5.1.

From Equation 8, $\widehat{\omega}<\underline{\omega} \leq \widehat{\omega}_{R}$. By Proposition 4 we can conclude that quality of public education has necessarily increased and, thus, that a strict Pareto improvement occurred.

All agents' disposable income increases $\left(t(\underline{\omega})<t^{n v}\left(\omega_{\text {med }}\right)\right)$; agents attending a private school (i.e., $\omega \in\left[\widehat{\omega}_{L}, \widehat{\omega}\right]$ and $\omega>\widehat{\omega}_{R}$ ) are better off with vouchers. The poorest agents $\left(\omega<\widehat{\omega}_{L}\right)$ are also better off, since they pay less in taxes and receive a better public service.

People in $\omega \in\left[\widehat{\omega}, \widehat{\omega}_{R}\right]$ could stick to the private market and consume a better bundle with respect to the one consumed without vouchers (since the tax decreased); if they move to the public sector, the WARP allows us to conclude that they are better off.

Because all agents are strictly better off, we conclude that the introduction of vouchers leads to a strict Pareto improvement.

The equilibrium when the majority of voters do not attend public school

When agents willing to attend public school are less than $50 \%$, the decisive voter belongs to the group of private school students profiting from the voucher. The minimum tax to finance vouchers for all agents entitled to receive them $\left(t=\frac{n_{p}^{n v} v}{\bar{\omega}}\right)$ 
wins any pair wise comparison. Replacing $v$ by its value, we obtain $t=\frac{n_{p}^{n v} v}{\bar{\omega}}=t^{n v}$. Every former student of the public school receives the average social cost of a public student in the no voucher case.

For this solution to represent a stable equilibrium, at least half of the population has to be better off; otherwise, this tax rate cannot win against the proposal of having no vouchers. All people with income $\omega>\widehat{\omega}$ are indifferent, since the tax does not change with respect to the benchmark.

People with income $\omega \in\left[\widehat{\omega}_{L}, \widehat{\omega}\right]$ are always better off (by WARP).

Concerning people with income $\omega<\widehat{\omega}_{L}$, they all receive the same voucher, to be spent for private education. There are three possible frameworks:

1. The private school market price $(q)$ is lower than the average cost of producing public education $\left(A C\left(X_{P}\right)\right)$ in the no-voucher case. It is socially optimal to dismantle the public school and distribute vouchers. Agents are better off, this solution is a Pareto improving, and public schooling disappears.

2. $q=A C\left(X_{P}\right)$. Agents are indifferent. This equilibrium weakly Pareto dominates the no-voucher case and public schooling disappears.

3. $q>A C\left(X_{P}\right)$. Voters with income $\omega<\widehat{\omega}_{L}$ are worse off (their consumption of the numeraire is constant, but they receive worse educational service). A minority of the population is worse off $\left(\omega<\widehat{\omega}_{L}\right)$, another is better off $\left(\omega \in\left[\widehat{\omega}_{L}, \widehat{\omega}\right]\right)$ and the remainder $(\omega>\widehat{\omega})$ is indifferent. For this framework to constitute an equilibrium (i.e., for voters to accept the introduction of vouchers), at least half of voters should agree on vouchers, which means that a substantial part of the richest agents must form a coalition with the middle class against the lower class.

\section{Conclusions}

Consider proposing to students in public school a voucher of value below the per student cost of providing free public education to be used to attend a private school. For each student opting for a private school, the government incurs in a net saving, which can be redistributed among all voters. Some agents accept the voucher because, by attending a private school, they choose the quality of instruction while public school only provides one level.

I investigate the implications of introducing selective vouchers and, in particular, whether the majority of voters would accept this change. I show that: 
1. the usual conclusion that the median voter is always decisive under SDI is not robust with regard to the introduction of vouchers.

2. in addition to the known coalition types (poor versus rich, or middle class versus the others), a third type of coalition can form. The middle class splits in two groups: the bottom one joins the richest agents, to ask for a reduction in taxes. Meanwhile, the top one forms a coalition with the poorest voters in order to increase taxes.

3. introducing selective vouchers induces a Pareto improvement unless i) this provokes the public sector collapse; and ii) the market price of private education is higher than the average cost of producing public education; in this case, the poorest in the population are hurt by vouchers.

4. a large majority should always support selective vouchers.

5. the middle class is the group that directly profits from vouchers; the poorest class bears their costs when public education disappears. The richest class weakly profits from the introduction of vouchers (through tax reductions).

The introduction of vouchers should never harm society (unless public school collapses), provided that the mechanism is properly designed. This result depends on the initial specifications: 1) it is not harmful for society to have people attending the school of their choice, ${ }^{31}$ and 2) peer effects are irrelevant (alternatively, peer effects have a linear impact on instruction).

Introducing selective vouchers of fixed amount implies a jump in utility (i.e., a distortion) for agents whose income is close to the threshold for eligibility. This is a structural problem of selective vouchers that can be avoided through introducing vouchers that are regressive in income. Further research may investigate the conditions under which such vouchers would be compatible with public budget constraint and induce an increase in welfare.

The introduction of vouchers increases integration in a stratified society, increasing the variance in wealth among students in the same school (making private schools accessible to poorer people and public schools more attractive for wealthier people).

From these results, voters should welcome the introduction of vouchers. Nevertheless, in many countries (especially in Europe), vouchers are not popular, as

\footnotetext{
${ }^{31}$ For instance, if a school were less effective in the spread of knowledge, increasing its market share might have a negative impact on productivity, growth, etc.
} 
demonstrated by the results of the Swiss referendum and the Italian debate over the last years. A combination of different factors may have generated this aversion. Private institutes can have religious or political orientations. Vouchers are sometimes perceived as a subsidy to a specific credo or as a way to diffuse specific cultures or principles, rather than a way to enlarge agents' possibility set.

Furthermore, often universal vouchers have been proposed. These are more likely to decrease the quality of public service and reduce redistribution.

Finally, a more substantial problem concerns the value of the voucher. A voucher of a small amount is ineffective, and a too large amount implies that public provision is no longer supported by the majority of the population. In my model, the value of the voucher is set exogenously at a value that relaxes the public budget constraint when some students participate. It would be of interest, in future research, to compute the optimal value of the voucher and the one preferred by the majority.

\section{Appendix}

\section{A On the convexity of the cost function}

Assumption 4 requires the cost function to be convex in the number of students (I use a strictly convex function, but local convexity, in a neighbourhood of the equilibrium, would be sufficient). Appendix A has two objectives: firstly (A.1) I show that convexity is an empirically relevant feature; empirical results are very controversial and I do not claim that the cost function is always convex. Still, I can show that convexity seems the most plausible assumption in some contexts. Then I show (A.2) that convexity is less crucial than it appears. I provide the intuition for an alternative model leading to very similar results, to prove that convexity could be replaced by other assumptions without affecting results.

\section{A.1 The empirical results on convexity}

Convexity can occur at the district or at the school level; in my model, the two coincide (only one school is present). This makes sense in a local perspective (considering a public school and its neighbourhood), or under a medium term time horizon (free markets adjust rapidly, changing the number or location of public schools is longer and more complex, involving the cooperation of different bodies and possibly involving different jurisdictions). 
Incompatibility in results about convexity could derive from the difficulty to define and measure school quality (Heinesen (2005)). A second problem is the district size: the shape of the cost function might differ for small districts: a discontinuity in the function could explain this; alternatively, decreasing returns to scale might occur only after a given scale (Galles and Sexton (1995)).

Picard (2003)'s technical report includes a survey on the advantages and disadvantages of large districts and on the presence of (dis)economies of scale. Duncombe, Miner, and Ruggiero (1995) show that of all the districts in the New York area, only some among those with less than 500 students would experience economies of scale. Andrews, Duncombe, and Yinger (2002) also support the conjecture that scale economies are present for sufficiently small districts, while sizeable diseconomies of scale appear for large districts (above 15000 students). Following Heinesen (2005), there is some consensus on the presence of scale economies (at least for small districts) when estimating the cost function, while the same is not true when estimating the school production function, that is, when the outcome is school quality (as in my model). Heinesen (2005) reports of several papers $^{32}$ supporting the idea of decreasing returns to scale. Results in Ruggiero (1999) are even stronger: even without assumptions on public authorities' efficiency, the cost frontier is convex.

Empirical findings at the school and class level are not more clear cutting. Epple and Romano (1998) and Epple, Romano, and Sieg (2006) seem to support the idea of a convex cost function. On the role of classes size in education effectiveness, Lazear (2001) writes that "Blake (1954) summarised a literature where 35 studies found smaller class size was better, 18 found larger class size was better, and 32 were inconclusive."

The precise definition of educational services plays a major role in that. When considering teaching, a non-convex cost function is more likely. Conversely, modern schools provide numerous facilities including libraries, computer rooms, sport facilities, etc, often showing non linear costs. Transportation costs, in particular, matter in the choice of the optimal size of a school.

Smet (2001) considers education in Belgium. Separating the cost of teaching from the other education related costs (transportation costs, in particular), Smet shows that the cost function is U-shaped. Consequently, there is an optimal size for schools, and the cost of education increases more than proportionally with the number of students, when the size of a school is excessive; especially because, for

\footnotetext{
${ }^{32}$ Driscoll, Halcoussis, and Svorny (2003), Ferguson (1991), Jacques, Brorsen, and Richter (2000), Kiesling (1967), Niskanen (1998), Walberg and Fowler Jr. (1987).
} 
a given distribution of the population, increasing the school size implies to attract students with larger transportation costs.

Chubb and Moe (1990), about the state of New York, conclude that public schools are not efficient and the size of school is not optimally chosen. Kokkelenberg, Dillon, and Christy (2008) conclude that "there are diseconomies of scale with a deterioration of the school quality outcome as class sizes grow larger".

Concluding, both at the school and district level, the empirical literature cannot provide a unique answer about the shape of the cost function. Fixed costs and some efficiencies in agglomerating call for sufficiently large schools and districts, but after a given threshold, diseconomies are not unfrequent in some countries. The way the educational bundle is defined has an impact on results: considering only the teaching service, the cost function seems to be more concave. Considering education (as in my model) as a consumption good, the impact on the cost function of complementary services (transport, organisational and security costs, etc.), a convex function seems more appropriate.

\section{A.2 Getting rid of convexity: intuition of an alternative model}

The convexity assumption is not as crucial as it might appear at first sight. This subsection is meant to give an intuition of one alternative model in which, with a linear cost function, the introduction of selective vouchers lead to a Pareto improvement. This is not a standing alone model, I simply describe the framework and the underlying mechanism.

Since private schools are costly, why some people attend them? One possibility is that they provide a better service (vertical differentiation); I rather consider a case of horizontal differentiation. If private schools provide additional services differently valuable to the population (religion or ethnical classes, for instance), the willingness to pay for private school differs from an agent to another.

Assume that the education production function exhibits constant marginal costs; quality depends on the per capita expenditure. Suppose, for instance, that in public schools the national language is used as the official language of instruction, while private schools propose a broad set of languages of instruction. While quality (and thus the production cost) is the same, the utility for citizens of attending a private school might change. Types determine how agents value the opportunity to choose the language of instruction. For simplicity, assume that richer people value more the freedom of choice, which means that the willingness to pay for 
private school increases in income.

I now define two agents (or level of income) that are crucial for the following explanation. The first is the usual indifferent voter, denoted by $\hat{\omega}$. The second one is the agent that (equalising the marginal utility of education and of the numeraire) would find it optimal to use all his disposable income for the numeraire and to consume exactly the level of education provided by public school (by the voting mechanism to choose the tax rate, this agent is the decisive/pivotal agent): I denote this voter as $\omega_{d}$. The pay-twice system for which private school students pay both the tax to finance public school and the tuition, implies that the indifferent voter has a marginal utility of private education larger than its marginal cost, because of the outside opportunity of attending public school for free (net of the sunk cost of the tax).

Private education, for a same level of quality (and thus of expenditure), guarantees a larger utility (because it allows to choose the language of instruction). Therefore, agent $\omega_{d}$ can be made indifferent with a voucher that allows him to keep his expenditure for the numeraire constant and to consume a specific level of education, which is lower than the one of public school, thus cheaper, but that gives the same level of utility (because of the increase in freedom). Consequently, the voucher can be of strictly smaller value than the cost of providing public education. The indifferent voter, by definition, is indifferent between attending public or private school, therefore, it is possible to convince him to attend a private school at no expense. The cost of convincing an agent to opt out of the public system is decreasing in income. Proposing to all agents in public school the voucher that that makes $\omega_{d}$ indifferent, agents with income $\omega \in\left(\omega_{d}, \hat{\omega}\right)$ use the voucher to move to a private school; the public sector saves (for each of these agents) the difference between the marginal cost of a student in the public school and the value of the voucher. The savings would imply, in the voting equilibrium, an increase in the quality of public school, and a decrease in the tax rate. Consequently all agents would be better off.

\section{B The effects of a change in the tax}

Most variables are affected by changes in the income tax. Intuitively, if the tax rate falls, the first impact on the model is that public investment in education $(t \bar{\omega})$ falls, and agents' disposable income $((1-t) \omega)$ increases. Both effects imply that opting for private school becomes more attractive. Concerning the first effect, the reasons 
are obvious, while for the second one, they are slightly more subtle: an increase in the disposable income leads to an increase in the consumption of $b$ for everybody, but since the quantity of $b$ consumed by people attending public school is higher, by the concavity of the utility function, the increase in utility for people attending public school is lower than the utility for those preferring private education. Since private school becomes more attractive, a greater number of agents switch from the public to the private system (which means that the income of the two indifferent voters decreases). The number of voters using vouchers increases, tightening even more the public budget constraint. Simultaneously, with the number of people attending public school having fallen, the per-capita public expenditure increases (since $g n_{p}$ drops), making public education more attractive.

To summarise, the impact on the quality of public school from a change in the tax is a priori undetermined: the budget available for public school is lower; meanwhile, the number of people attending public school decreases (both because public school becomes less attractive and because agents' disposable income increases). When $\frac{\partial X_{p}}{\partial t} \geq 0$, it means that a reduction in the tax rate decreases public expenditure for education and the consequent shrinkage in the number of people attending public school is not enough to offset it (demand for public school is inelastic); thus, the per-capita expenditure will also plunge. The reverse is true for $\frac{\partial X_{p}}{\partial t}<0$.

\section{Proof of Proposition 1}

At equilibrium, $n_{p}$ has to solve two equations. On one side, it is equal to the fraction of agents for whom the utility of attending a public school is larger than the utility of opting out of it, thus $n_{p}=\mu\left\{\omega: U^{P}\left(t, \omega, \bar{\omega}, n_{p}\right) \geq U^{R}(t, \omega, v)\right.$, where $\mu$ is the probability measure associated with the distribution function. On the other hand (Equation 7), the number of agents with income in the interval $\left[\omega_{\min }, \widehat{\omega}_{L}\right] \cup\left[\widehat{\omega}, \widehat{\omega}_{R}\right]$ must be the same as the value for $n_{p}$ used by agents to solve their maximisation problem.

Equating the two, we obtain $\mu\left\{\omega: U^{P}\left(t, \omega, \bar{\omega}, n_{p}\right) \geq U^{R}(t, \omega, v)=F\left(\widehat{\omega}_{L}\right)+\right.$ $\left(F\left(\widehat{\omega}_{R}\right)-F(\widehat{\omega})\right)$. Simple computations show that the left-hand side of the equation is decreasing in both $\widehat{\omega}_{L}$ and $\widehat{\omega}_{R}$ while the right-hand side is increasing. Since $F$ is a continuous (and strictly increasing) function and since, for $n_{p}=0$, the left-hand side is always larger than the right-hand side, a unique solution exists (fixed point theorem). 


\section{Proof of Proposition 2}

For a given revenue $\widetilde{\omega}$, the preferred tax $t(\widetilde{\omega})=\arg \max _{t} U^{P}\left(\frac{t \bar{\omega}-n_{v} v}{g n_{p}},(1-t) \widetilde{\omega}\right)$. If, for any reason, the first argument $\left(X_{p}\right)$ increases, its marginal utility of education $\left(U_{1}^{p}\right)$ decreases. At equilibrium, the optimal tax by definition equalises the marginal utility of both arguments $\left(U_{1}^{p}=U_{2}^{p}\right)$, which means that the marginal utility of the numeraire falls (thus, the numeraire consumption has to increase) and thus the tax drops.

\section{E Proof of Proposition 3}

If $\widehat{\omega}_{L}=\widehat{\omega}$, nobody uses the voucher, $n_{v}=0$ and $X_{p}=\frac{\bar{\omega} t^{n v}}{g n_{p}}$. The number of students attending public school cannot be lower than in equilibrium in the novoucher case, which implies that $g n_{p} \geq g^{n v} n_{p}^{n v}$. This makes public school (weakly) less attractive than in the no-voucher case, so all the households with income $\omega>\widehat{\omega}$ (who were already preferring the private system) confirm their choice. If $X_{R} \succ_{\omega} X_{P}$ for all $\omega>\widehat{\omega}$, then $g^{n v} n_{p}^{n v}=g n_{p}$ and thus $X_{p}^{v}=X_{p}$ and we are back to the equilibrium case without vouchers.

Finally, it cannot be that $\widehat{\omega}_{L}>\widehat{\omega}$. This would result in $n_{v}=0$ and $g^{v} n_{p}^{v}=g n_{p}$; this would imply that $X_{P}^{n v}=X_{P}$ and thus that $\widehat{\omega}_{L}=\widehat{\omega}$, which is a contradiction. This proves that $\widehat{\omega}_{L} \leq \widehat{\omega}$ in all cases.

\section{F Proof of Proposition 4}

$X_{P}>X_{P}^{n v} \Leftarrow \widehat{\omega}_{R}>\widehat{\omega}$ : if $\widehat{\omega}_{R}>\widehat{\omega}$, agents in the interval $\left(\widehat{\omega}, \widehat{\omega}_{R}\right)$ are attending public school in the presence of vouchers while they were attending private schools before. The introduction of vouchers does not imply changes in the disposable income of agents with income above $\widehat{\omega}$; thus the original consumption bundle remains affordable. By the WARP, if we observe a change in this agents' behaviour, it must be that the new bundle is preferred. Since the numeraire consumption is constant, it must be that the quality of school consumed has increased, thus $X_{P}>X_{R}>X_{P}^{n v}$.

$X_{P}^{n v}=X_{P} \Rightarrow \widehat{\omega}_{R}=\widehat{\omega}$ : when $X_{P}^{n v}=X_{P}$, for agents in $\left(\widehat{\omega}, \omega_{\max }\right]$ nothing has changed. By simply replacing $X_{P}$ by $X_{P}^{n v}$ in equation 6 , we are back to the condition in equation 3 , and thus, by definition, the solution of the problem is $\widehat{\omega}$.

$X_{P}>X_{P}^{n v} \Rightarrow \widehat{\omega}_{R}>\widehat{\omega}$ : by definition, $\widehat{\omega}_{R}$ is the level of income for which the left- 
and right-hand sides of Equation 6 are equal. For $X_{P}^{n v}=X_{P}, \widehat{\omega}_{R}=\widehat{\omega}$. Increasing $X_{P}$, public school becomes more attractive (i.e., the right-hand side is bigger than the left-hand side). Only an increase in the level of income can re-establish the equality. Such an increase leads to a higher consumption of the numeraire both in the case of consumption of public school and that of private school; given the concavity of the utility function, the marginal increase is higher on the left-hand side than on the right-hand side, which ensures that for a sufficiently large increase in $\widehat{\omega}_{R}$, the equality holds once again.

\section{G Proof of Proposition 5}

By Proposition $3, \widehat{\omega}_{L}$ cannot be greater than $\widehat{\omega}$. Two different scenarios are possible: $\widehat{\omega}_{L}=\widehat{\omega}$ or $\widehat{\omega}_{L}<\widehat{\omega}$.

Proof by contradiction. Suppose $\widehat{\omega}_{L}<\widehat{\omega}$ and $X_{P} \leq X_{P}^{n v}$ : by Proposition 4, $\widehat{\omega}_{R}=\widehat{\omega}$ and thus a) $n_{p}=\left(n_{p}\left(t^{n v}\right)-n_{v}\right)$, b) $\omega_{m e d}$ is decisive, c) $t>t^{n v}$ and d) $g<g^{n v}\left(\right.$ since $\left.\widehat{\omega}_{L}<\widehat{\omega}\right)$.

Then

$$
\left[\frac{t^{n v}}{g^{n v} n_{p}^{n v}}-\left(\frac{t-\frac{n_{v}}{n_{p}^{n v}} t^{n v}}{g n_{p}}\right)\right] \bar{\omega}>0
$$

a necessary condition for that ( since $t>t^{n v}$ ) is $n_{p} g+n_{v} g^{n v}>n_{p}^{n v} g^{n v}$. For this to be true it must be that $g>g^{n v}$ which is impossible. 


\section{References}

Andrews, M., W. Duncombe, and J. Yinger (2002). Revisiting economies of size in education: Are we any closer to a consensus? Economics of Education Review 21, 245-262.

Blake, H. (1954). Class Size: A Summary of Selected Studies in Elementary and Secondary Public Schools. Ph. D. thesis, Columbia University.

Blomquist, S. and V. Christiansen (1999). The political economy of publicly provided private goods. Journal of Public Economics 73 (1), 31-54.

Budge, I. (2006). Direct and representative democracy: are they necessarily opposed? Representation 42, 1-12.

Burke, M. A. and T. R. Sass (2008). Classroom peer effects and student achievement. Technical Report WP18, Urban institution.

Card, D. and A. Krueger (1992). Does school quality matter? Returns to education and the characteristics of public schools in the United States. Journal of Political Economy 100, 1-40.

Chakrabarti, R. (2008, June). Can increasing private school participation and monetary loss in a voucher program affect public school performance? Evidence from Milwaukee. Journal of Public Economics 92(5-6), 1371-1393.

Chen, Z. and E. G. West (2000). Selective versus Universal Vouchers: Modeling Median Voter Preferences in Education. American Economic Review 90(5), 1520-1534.

Chubb, J. E. and T. M. Moe (1990). Politics, markets, and America's schools. Brookings Institution.

Cox, C. and M. J. Lemaitre (1999). Chile: recent policy lessons and emerging challenges, Chapter Market and state principles of reform in Chilean education: policies and results, pp. 159-188. The World Bank, Washington DC.

De Fraja, G. (2002). The design of optimal education policy. Review of economic studies 69, 437-466.

Driscoll, D., D. Halcoussis, and S. Svorny (2003, April). School district size and student performance. Economics of Education Review 22(2), 193-201.

Duncombe, W., J. Miner, and J. Ruggiero (1995). Potential Cost Savings from School District. Economics of Education Review 14, 365-284. 
Dur, R. and A. Glazer (2008). Subsidizing Enjoyable Education. Labour Economics 15, 1023-1039.

Epple, D. and R. Romano (1996). Ends against the middle: Determining public service provision when there are private alternatives. Journal of Public Economics 62(3), 297-325.

Epple, D. and R. Romano (1998). Competition between Private and $\mathrm{Pu}-$ blic Schools, Vouchers, and Peer-Group Effects. American Economic Review $88(1), 33-62$.

Epple, D., R. Romano, and H. Sieg (2006). Admission, Tuition, and Financial Aid Policies in the Market for Higher Education. Econometrica 74, 885-928.

Ferguson, R. (1991). Paying for public education: new evidence on how and why money matters. Harvard Journal of Legislation 28, 466-498.

Filer, R. K. and D. Munich (2001, February). Responses of private and public schools to voucher funding: the Czech and Hungarian experience. HEW 0012002, EconWPA.

Galles, G. M. and R. L. Sexton (1995). Diseconomies of school district size. Journal of Social, Political and Economic Studies 20, 241-245.

Glomm, G. and B. Ravikumar (1992). Public versus private investment in human capital. Endogenous growth and income inequality. Journal of Political Economy 100, 818-834.

Glomm, G. and B. Ravikumar (1998). Opting out of publicly provided services: A majority voting result. Social choice and welfare 15, 187-199.

Gradstein, M. and M. Justman (2002). Education, Social Cohesion, and Economic Growth. The American Economic Review 92(4), 1192-1204.

Gradstein, M., M. Justman, and V. Meier (2005). The political economy of education. MIT press.

Hanushek, E. and F. Welch (Eds.) (2006, November). Handbook of the Economics of Education. Elsevier.

Heinesen, E. (2005). School district size and student educational attainment: evidence from Denmark. Economics of Education Review 24, 677-689.

Jacques, C., B. W. Brorsen, and F. G. C. Richter (2000). Consolidating rural school districts: Potential savings and effects on student achievement. Journal of Agricultural and Applied Economics 32, 573-583. 
Kiesling, H. J. (1967). Measuring a government service: School districts in new york state. Review of Economics and Statistics 49, 356-367.

Kokkelenberg, E. C., M. Dillon, and S. M. Christy (2008). The effects of class size on student grades at a public university. Economics of Education Review 27, 221-233.

Lazear, E. (2001). Educational production. Quarterly Journal of Economics 116, $777-803$.

McEwan, P. J. (2003). Peer effects on student achievement: evidence from Chile. Economics of Education Review 22, 131-141.

McEwan, P. J. and M. Carnoy (2002). The effectiveness and efficiency of private schools in Chile's voucher system. Educational Evaluation and Policy Analysis 3, 213-239.

Niskanen, W. A. (1998). Policy analysis and public choice, Chapter Student performance and school district size, pp. 124-134. Edward Elgar Publishing.

OECD (1998). Education at a glance. OECD.

Picard, C. (2003). Small school districts and economies of scale. Technical report, Louisiana Department of Education.

Ruggiero, J. (1999). Nonparametric analysis of educational costs. European Journal of Operational Research 119, 605-612.

Smet, M. (2001). Determining the optimal size of study fields in Flemish secondary education. Economics of Education Review 20, 443-457.

Stiglitz, J. E. (1974). The Demand for Education in Public and Private School Systems. Journal of Public Economics 3, 349-385.

Walberg, H. J. and W. J. Fowler Jr. (1987). Expenditure and size efficiencies of public school districts. Educational Researcher 16, 5-13.

Zimmerman, D. J. (2003). Peer Effects in Academic Outcomes: Evidence from a Natural Experiment. The Review of Economics and Statistics 85(1), 9-23. 